\title{
Study on General Pattern of Attacking the Goal for Each Team in the Final of the 15th Europe Cup
}

\author{
Nie Shangwei \\ Physical Education \\ Chengdu University of TCM \\ Chengdu 611137
}

\begin{abstract}
This paper makes a statistical analysis of the characteristics of 105 goals scored in 51 games in the final in 15th Europe Cup by adopting the methods of literature material and data statistics. And the results indicate that: the total goals of 15th Europe Cup is higher than the previous session; the average goals in each game is slightly lower than the previous session; the goals scored in second half is more than the first half; the first $\mathbf{1 5}$ minutes in the second half are the highest peak of goals in the whole game; strikers are the top scorers among each positions; the success rate of the football attacks in fore court and the middle attack rank first in among attack forms; shooting goal is the top choice of the way of goal for players; shooting area is mainly focused on the penalty area; the bottom left and right of the goal are the two areas with the highest rate of goals.
\end{abstract}

Keywords_Europe Cup; football; 15th; goal; characteristic

\section{INTRODUCTION}

The 15th European Football Championship was held in France. 24 soccer teams are reached the Europe Cup finals for the first time, which was divided into 6 groups and the game was under group single cycle point system. Only the top two and four of the best third-placed teams from the six groups advance to the round of 16 elimination match. Through the statistical analysis of the characteristics of goals, goal-time, way of goals, attacking method, position of goal scorer, strike area and shooting area of the of 105 goals scored in 51 games by 24 teams in the final in European Football Championship of 2016, which do not include 3 own goals and 28 goals scored in penalty kicks, this paper aims at revealing the general rules and characteristics of the current European Football Championship and providing a theoretical basis for the future training of Chinese football and shooting in games.

\section{Research OBJects AND Methods}

This paper makes a statistical analysis of the characteristics of 105 goals scored in 51 games by 24 teams in the final in 15th Europe Cup by adopting the methods of literature material

The Shooting zone and goal area division diagram. In order to facilitate making an objective description and analysis of the characteristics of goal positions, shooting zone and goal area are specially divided as the following Fig. 1 and Fig. 2.

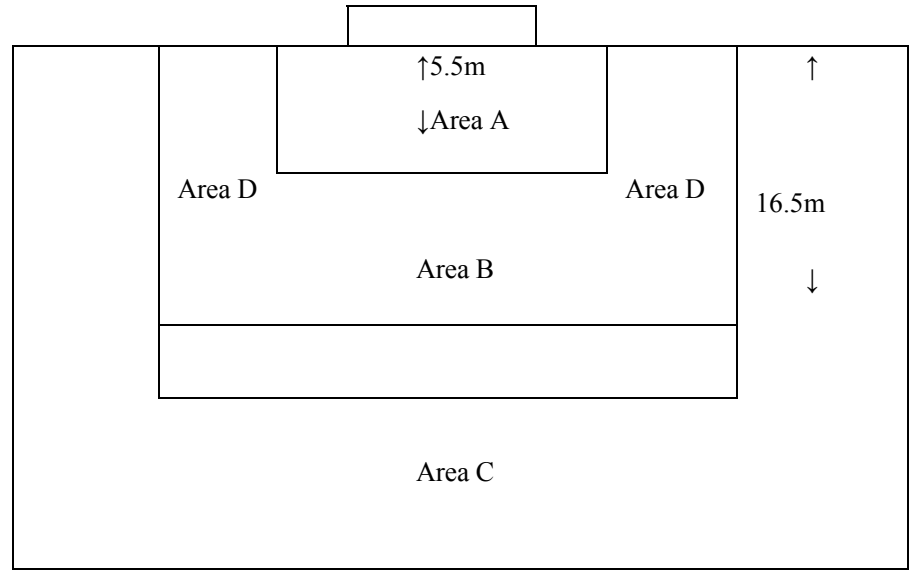

Fig. 1. Shooting Area Schematic

\begin{tabular}{|c|c|c|}
\hline$\leftarrow$ & $7.32 \mathrm{~m}$ & \\
\hline 1. upper left & 4. upper-middle & 7. right upper \\
\hline 2. Middle Left & 5. middle & 8. Middle Right \\
\hline 3. lower left & 6. lower-middle & 9. lower right \\
\hline
\end{tabular}

Fig. 2. Goal Area Schematic

\section{RESUlTS AND ANALYSIS}

\section{A. Characteristics of goal-time}

Based on the statistical data of goal-time from Fig. 1, there are 42 goals in the first half of this Europe Cup, which accounts for $40 \%$ of the total goals. And there are 61 goals in the second half, which accounts for $58.1 \%$ of the total goals. There are 2 goals in overtime, which accounts for $1.9 \%$ of the total goals. Obviously, the rate of goals of second half is much higher than the first half. According to an average time quantum of 15 minutes, one 90-minutes game can be divided into 6 time intervals, and plus one overtime, two injury times of the first half and the second half. Goal-time of 9 time intervals can be analyzed. It is observed that the physical stamina of players can be timely supplemented and recovered through the timing adjustment of the half time interval, through which the players can injected them into the game. They have fully adapted to the 
rhythm of the game, with a comparative balance of attentiveness and physical ability distribution and a relatively stable state. And coach will make pertinent deployment based on the technical and tactical characteristics of the opponents showed in the first half. Therefore, the first 15 minutes in the second half is the highest peak of goals in the whole game, which accounts for $20 \%$ of the total goals. Secondly, in the closing 15 minutes of the first half and the second half are the time intervals with high rate of goals, which accounts for $18.1 \%$ of the total goals. Based on the actual game, in these two time intervals, there are several main reasons for losing the ball: athlete's physique declines; players cannot fully concentrate; system of defense is relatively loose; defensive action is not arriving; defense matrix is easily broken. In the first 15 minutes of the first half, players of each team have good stamina, and midfield players and forecourt players are aggressive. Defensive positioning cannot totally keep up with the hard impact of quick attack. Therefore, 13 goals were scored, which has become the second most time interval of goals in the first half. In the time interval of 16 minutes to 30 minutes, because both teams have experienced a process of exploring and getting familiar with the field, and both teams have adapted to the tactics, formation and styles of the opponents, the attack and defense transformation is steady and there are fewer goals, which accounts for $8.57 \%$ of the total goals. Among the nine statistical intervals, the one with the least goals is the injury time of the first half. There is only one goal scored in this time interval in 51 games. It is observed that each team is relatively concentrated in this key period. Nobody wants to loose ball regretfully because of relaxing and cause a passive state for the beginning of the second half. In the time interval of 61 minutes to 75 minutes of the second half, each team has showed their distinct technical and tactic characteristics. Both ends in the field are aggressive and the goals are relatively stable, which accounts for $13.33 \%$ of the total goals. Injury time of the second half is the vital time interval of the game, perhaps even is the decision period of the whole game. Especially if the team in a draw or the team which is fallen behind could grasp this time period, it is able to turn the things around and lead to the final success. Therefore, each team is paying particular attention to this period. Besides the competition of techniques and tactics, each team strengthens their comprehensive battle of physical ability and willpower. There are 7 goals in this time interval, which accounts for $6.67 \%$. Overtime is the moments of great anxiety in the whole game. Besides testing the stability of techniques and tactics of each ends, the physical ability, willpower and psychological quality are highly required. In this Europe Cup, only 2 goals are scored in this time interval. Coincidentally, these two goals are all scored by Portugal, which is the final champion. One was in the eighth-finals with Croatia, which was arrived in the 117th minute when the forward Quaresma give a follow shot after Cristiano Ronaldo's shot. Another was in the final game, which was arrived in the 109th minute when the substitute Ade running with ball through center and shooting the bottom left of the goal form distance. And this shot has won the host country France. Both the two goals have clearly manifested the super powers of physical ability and tactical capability of the champion team. Especially in the grueling stalemate, the powerful abilities of controlling the game and grasping the opportunity of shooting from distance are the crux of leading the team squad to the ultimate title.

TABLE I. GOAL-TIME IN THE FINAL IN 15TH EUROPE CUP STATISTICS TABLE

\begin{tabular}{|c|c|c|c|c|c|c|c|c|c|}
\hline & $0 \sim 15 \mathrm{~min}$ & $16 \sim 30 \mathrm{~min}$ & $31 \sim 45 \mathrm{~min}$ & $\begin{array}{l}\text { Overtime in } \\
\text { the first half }\end{array}$ & $46 \sim 60 \mathrm{~min}$ & $61 \sim 75 \mathrm{~min}$ & $76 \sim 90 \mathrm{~min}$ & $\begin{array}{c}\text { Overtime in } \\
\text { the second } \\
\text { half }\end{array}$ & $\begin{array}{c}\text { Overti } \\
\text { me }\end{array}$ \\
\hline $\mathrm{n}$ & 13 & 9 & 19 & 1 & 21 & 14 & 19 & 7 & 2 \\
\hline $\begin{array}{c}\text { Propor } \\
\text { tion }\end{array}$ & $12.38 \%$ & $8.57 \%$ & $18.10 \%$ & $0.95 \%$ & $20.00 \%$ & $13.33 \%$ & $18.10 \%$ & $6.67 \%$ & $1.90 \%$ \\
\hline
\end{tabular}

\section{B. Characteristics of way of goals}

Based on the Table 2 of the Way of Goals in the Final in 15th Europe Cup Statistics Table, it can be seen that there are 82 goals scored by foot of the players in the 105 goals in the Final in 15th Europe Cup, which accounts for $78.1 \%$ of the total goals, and 23 headings, accounting for $21.9 \%$ of the total goals. Shooting in foot is still the major technical means of attacking scores in modern European Football, among which, the positioning shot in foot takes a proportion of $30.48 \%$. A slightly increase occurred than the previous Europe Cup, and it still ranks the first among all the way of goals. Catching a ball and adjustment to shoot in foot ranks the second. With a relatively high rate of goals, it takes a proportion of $25.71 \%$. The proportion of breakthrough of dribble and shot in foot takes a proportion of $10.48 \%$ of the total goals. There are 4 direct free kicks and 8 ball-point shots, which accounts for $3.81 \%$ and $7.62 \%$ respectively. Heading with a proportion of $21.9 \%$ ranks the third among all the way of goals.

The statistical data has revealed that the consciousness of cutting in for goal of each team of this Europe Cup is relatively strong and the technical quality of shooting before the goal is extremely high. Once the full back of one team loss the opportunities of failing to defend or miskick, the forward players of the adversary team will give the positioning shot in foot directly. Based on the actual game on the fields, many goals were pushed shooting easily by the players through running with ball or adjusting slightly after receiving the ball and going past the defender or even the goalkeeper. This has also indicated that the mature and stable mental on attacking and shot of players in each team of this Europe Cup. They were clam before shoot, and their shot technique of running with ball is excellent and adept [2]. Based on the lower rate of goals of other foot shot methods, it can be reflected that each team of this Europe Cup has reinforced attacking as well as defending with full backs. And the defensive ability is relatively strong, especially the midfielders and full backs can defend synergistically and effectively, and the success rate of disorganizing the cooperating goal-shooting. Sometimes they have forced the opponent to make adjustments and then shooting or carry on the tactic to violate a regulation, which has led to the penalty kick spot kicks. Therefore, the situation of 
centering on cutting in for goal with less other shooting methods is occurred.

It is also worth noting that the goals of heading is much more than other ways of shooting in foot, which is one of the three major ways of goals. With the severe competition of European football, the occupation and control of the area in front of goal of each team are mainly reflected in the techniques of heading. Heading cutting in for goal is naturally become an important method, which is the necessary reflections of pursuing the multi-dimensional and threedimension tactical play of the European soccer power. Besides, it also matches the following characteristics: European football players are tall of stature; their physical constitution is good; they have great capability in football's high operations; their heading techniques are increasingly skilled. Therefore, the additional strength of heading cutting in for goal in game and the shooting may have a head start if the team has grasped the rule, and it will lay a solid foundation for the success of the whole game [5].

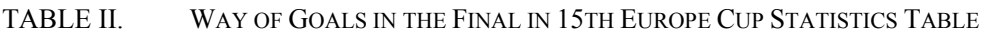

\begin{tabular}{|c|c|c|c|c|c|c|c|c|c|c|c|c|}
\hline \multirow[t]{2}{*}{ Total } & \multicolumn{2}{|c|}{$\begin{array}{l}\text { positioning shot in } \\
\text { foot }\end{array}$} & \multicolumn{2}{|c|}{$\begin{array}{l}\text { catching a ball and } \\
\text { adjustment to } \\
\text { shoot in foot }\end{array}$} & \multicolumn{2}{|c|}{$\begin{array}{l}\text { breakthrough of } \\
\text { dribble and shot in } \\
\text { foot }\end{array}$} & \multicolumn{2}{|c|}{ direct free kick } & \multicolumn{2}{|c|}{ ball-point shot } & \multicolumn{2}{|c|}{ heading } \\
\hline & $\mathrm{n}$ & Proportion & $\mathrm{n}$ & Proportion & $\mathrm{n}$ & Proportion & $\mathrm{n}$ & Proportion & $\mathrm{n}$ & Proportion & $\mathrm{n}$ & Proportion \\
\hline 105 & 32 & $30.48 \%$ & 27 & $25.71 \%$ & 11 & $10.48 \%$ & 4 & $3.81 \%$ & 8 & $7.62 \%$ & 23 & $21.90 \%$ \\
\hline
\end{tabular}

\section{Characteristics of attacking form}

Based on the characteristics of modern football, the attacking tactics form can be divided into the following three ways: side attack in the movement; centre attack; attacking set pieces [6].The Attacking Forms in the Final in 15th Europe Cup Statistics Table has indicated that the attack forms in movement are opposite with the previous Europe Cups, and the side attack has become the mainstream attack form, with a rate of goals nearly doubled than the centre attack. Therefore, in this Europe Cup, side attack has played an important role in the offensive tactical system. Attacking set pieces has also played an important role, which accounts for $1 / 3$ of the total goals. Besides, the goals of side attack and attacking set pieces is 80 , which accounts for $76.19 \%$ (see Table 3 ), and they have also played an important role. It is observed that side attack and attacking set pieces are the best ways of scoring play, which has become the development trend of the attacking form in the modern European football.

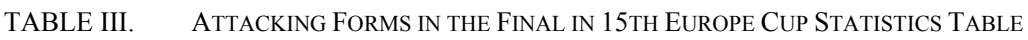

\begin{tabular}{cccccccc}
\hline & \multicolumn{2}{c}{ Attack in the movement } & & \multicolumn{4}{c}{ attacking set pieces } \\
\cline { 2 - 3 } \cline { 6 - 8 } & sideways & middle & & $\begin{array}{c}\text { corner } \\
\text { kick }\end{array}$ & $\begin{array}{c}\text { penalty } \\
\text { kick }\end{array}$ & free kick & throw-in \\
\hline goals & 47 & 25 & & 12 & 8 & 11 & 2 \\
Proportion $\%$ & $44.76 \%$ & $23.81 \%$ & & $11.43 \%$ & $7.62 \%$ & $10.48 \%$ & $1.90 \%$ \\
\hline
\end{tabular}

Through watching the application of spot tactics of each team in video, it can be seen that each team is fiercely striving for the ball in the midfield and fore court; especially they have poured players in the penalty box. Men-to- men blanket defense was adopted. Thus each team is able to transfer to the side and set up an offense in the opposing and measuring by using spot tactics, and also create more chance for the side attack. At the meantime, more chances of penalty kick and direct free kick will be created in the defensive process in fore court, and the goals of attacking set pieces will be increased accordingly. Bell in Wales has netted a free-kick in fore court in two consecutive games. Therefore, attacking set pieces has become one of the major attacking forms in European football, which should be paid high attention in the daily training and practice.

\section{Characteristics of the position of goal scorer}

Fig. 3 shows that half of the goals were scored by strikers in this Europe Cup, with 52 goals. Strikers remain the scoring point of main attack. 43 goals were scored by the midfield, which accounts for $41 \%$ of the total goals. 10 goals were scored by the defenders, which accounts for $9 \%$ of the total goals. It is clear that the goals scored by strikers, midfield and defenders are in a descending order, which has met the general regulation of distribution of goals in each position of modern football. However, an antigrowth tendency of the goals scored by strikers and midfield between this Europe Cup and the last Europe Cup was presented, that is to say the number of goals scored by midfield is increasing, while the number of goals scored by strikers is decreasing. It can be well illustrated combining with the tape-delayed of games. In this Europe Cup, each team pays more attention to the striving in midfield and fore court. Especially under the circumstance of the one-on-one defense of strikers, the strikers were clung. Thus they passed the ball to the midfield that is backing up them. This is the main reason why the rate of goals scored by midfield is increasing. From another point of view, the cooperation of each positions and the modern overall football idea was well explained. Compared with strikers and midfield, defenders have little goals. But the original specificity of pure defensing of defenders has changed. At the meantime, the following characteristics and tendency were reflected: all attack and all defenses of modern football; players' one specialty with multiple skills; comprehensive techniques and tactics and their utility [7]. In brief, modern football not only requires strikers, midfield and defenders could finish their own responsibility, but also requires them to be qualified for the multiple techniques and tactics of other positions. Each position has divisions of labor, but they are still complementary. A utility player with the ability of all attack and all defense has become the development law of the characteristics of position of modern Europe football[8]. 


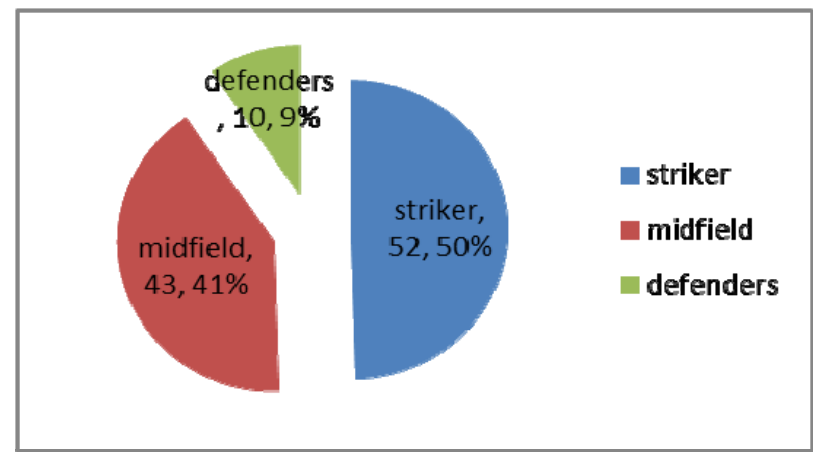

Fig. 3. Position of Goal Scorer in the Final in 15th Europe Cup Schematic

\section{E. Characteristics of the attacking area}

Attacking area refers to the area that one team start to organize the effective attack and push ahead after they get the ball and start attack from defense. Table 4 shows that midfield and fore court are the main attacking area in this Europe Cup. There are 80 goals scored, which accounts for $76.19 \%$ of total goals. 25 goals were scored in backcourt, which accounts for $23.81 \%$ of total goals, with an increasing of $7.81 \%$. This shows that the closer starting attack from the goal, the higher of the success rate will be. Through the analysis of the video games, we can know that each team pays attention of the striving for the ball in midfield and fore court, especially for the intensive defense toward the strikers. With the effectively adoption of total football in game, whole players of the offensive will go to the fore court to close them down with a purpose of get the ball. This is common, and leaves a good opportunity for the opposite side to start a fast-switching attack. In this Europe Cup, the crack Italian had capitalized several opportunities to start attacking from the backcourt and scored the scores. This characteristic has also revealed that while ensuring the competition in midfield and fore court in modern football games, the fast-switching attack in backcourt has become the effective way following after the attack in midfield and fore court [9].

TABle IV. AtTacking Area in the Final in 15Th Europe Cup Statistics Table

\begin{tabular}{|c|c|c|c|c|c|c|c|}
\hline \multicolumn{2}{|c|}{ attacking in fore court } & \multicolumn{2}{|c|}{ attacking in midfield } & \multicolumn{2}{|c|}{ attacking in backcourt } & \multicolumn{2}{|c|}{ penalty kick } \\
\hline goals & $\begin{array}{c}\text { proportio } \\
n\end{array}$ & goals & $\begin{array}{c}\text { proportio } \\
n\end{array}$ & goals & $\begin{array}{c}\text { proportio } \\
n\end{array}$ & goals & $\begin{array}{c}\text { proportio } \\
\mathrm{n}\end{array}$ \\
\hline 42 & $40.00 \%$ & 30 & $28.57 \%$ & 25 & $23.81 \%$ & 8 & $7.62 \%$ \\
\hline
\end{tabular}

\section{F. Characteristics of the entrance area}

Fig. 4 shows that lower left and lower right are the two areas with more goals in the final in the Europe Cup of 2016, which accounts for $22.86 \%$ and $28.57 \%$ of total goals respectively. It is followed by the middle left. Goals from other areas are less. Upper middle and middle are opposite to the position of the goalkeeper, with lowest number goals. Through the analysis of the video games, we can know that the straightline distance from lower left and lower right to goalkeeper is the farthest. In terms of the space, it is in the different level with the position of the goalkeeper's catching and diving. Although the judgment of goalkeeper is correct, the speed of squat will bring the difficulty for diving save. Thus the characteristic of high rate of goals occurs. In direct free kicks, most players will choose upper left and upper right to shoot. There are two main reasons after the analysis: firstly, as for the goalkeeper, these two areas are the "dead area" of the goal, because it is far from the defensive approach, and the wily angle has increased the difficulty for diving save; secondly, as for the attacking player, facing with the block of the "defensive wall" of the opposite team, upper left and upper right areas are more suitable for the bypassing of the "defensive wall" and the successful shooting. The comprehensive statistics has showed that upper left and upper right are the best choice for attacking free kicks, and lower left and lower right are the best entrance areas in this Europe Cup.

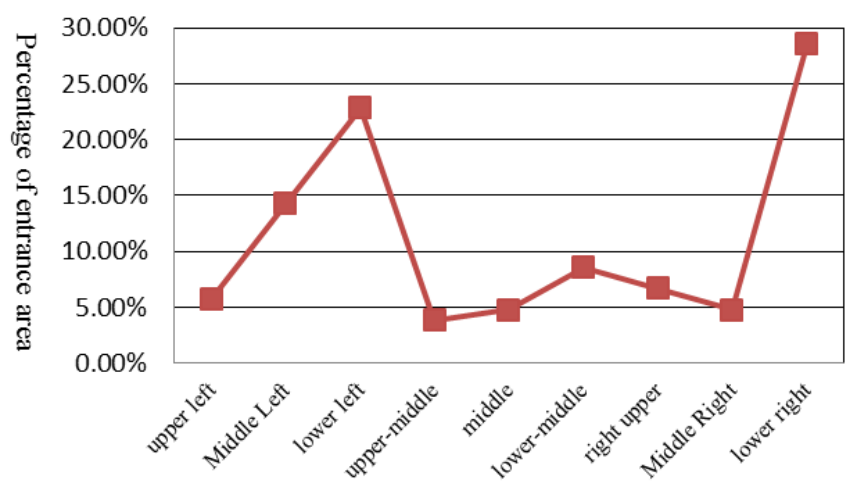

Fig. 4. Entrance Area in the Final in 15th Europe Cup Schematic

\section{G. Characteristics of the shooting area}

Fig. 5 shows that Area B is the main shooting area in the final in this Europe Cup, which accounts for $68.57 \%$ of total goals. It is followed by Area $\mathrm{C}$ with a proportion of $15.24 \%$. The nearest Area A had 14 goals, with a proportion of $13.33 \%$. Area D, which locates in the left and right side of the goal, had least goals because of the limited shooting angle. It had only 3 goals, which accounts for $2.86 \%$. Based on actual game, each team has paid more attention to and strengthened the opportunities of shooting in the execution of technique system. On one hand, Area B belongs to the limit of the prohibited area of penalty area. Once defensive foul occurs, they will get the opportunity of spot kick directly; on the other hand, this area is near to the goal, and the angle is fit, which has provided plenty angles and route for players to shoot. Thus the difficulty of judging the direction of the goalkeeper will be increased 
undoubtedly. Based on the data, it is known that the goals from Area $\mathrm{C}$ are more than that of the previous Europe Cup, which ranks the second in all the shooting areas. According to the video game, it is not difficult to see that Area A and Area B are close to the goal, of which the players are good at shooting. Cutting in for goal in foot and heading are all posing a huge threat for them. Therefore, Area A and Area B are the key defense area in games. When the game moves in a standoff and difficult to make a breakthrough from Area A and Area B, smart players always choose Area $\mathrm{C}$ to try a long shot because it is far away from the goal and the defending power is relatively loose. For example, in the overtime of the final, the striker Ade of Portugal slammed the ball past the defender on the edge of the penalty area and made a long shot to win the French team. In conclusion, nearby penalty area is still the most threatening shooting area. When the game moving in a standoff, the long shooting opportunity form the edge of the penalty area in front the goal should be grasped, which will enhance the ability of the long-shot and beneficial for the decisive role of victory or defeat played in game.

TABLE V. ShoOting AREA IN THE FINAL IN 15TH EUROPE CUP SCHEMATIC

\begin{tabular}{|c|c|c|c|c|c|c|c|c|}
\hline \multirow{2}{*}{ goals } & \multicolumn{2}{|c|}{ Area A } & \multicolumn{2}{|c|}{ Area B } & \multicolumn{2}{|c|}{ Area C } & \multicolumn{2}{|c|}{ Area D } \\
\hline & $\mathrm{n}$ & proportion & $\mathrm{n}$ & proportion & $\mathrm{n}$ & proportion & $\mathrm{n}$ & proportion \\
\hline 105 & 14 & $13.33 \%$ & 72 & $68.57 \%$ & 16 & $15.24 \%$ & 3 & $2.86 \%$ \\
\hline
\end{tabular}

\section{CONCLUSION}

1. The 15th European Cup scores a total of 105 goals at final stage, averaging 2.06 goals; lower than the previous number of goals per game.

2. The goals of the second half of the current European Cup finals were significantly more than the first half. The $15 \mathrm{~min}$ session after the start of the second half scores the most, next is the 15 min session near the end of the first and second half, the rest of the time scores rate less.

3. Foot shot is the main way to score, in which foot shot on sight has the highest rate of goals. Heading technique has become one of the three major scoring ways, which is also a important technical means to constitute modern European football multi-dimensional tactical system.

4. It has the opposite offensive form compared to the past European Cup. The wing attack is the mainstream offensive form of the current European Cup. Attacking set pieces plays an important role in the game, its number of goals accounting for about $1 / 3$ of the total number of balls. Wing attack and attacking set pieces are the best ways of offensive tactical score in the current European Cup, the rational integration of the two ways reflects the development trend of modern European football attacking tactics.

5. The striker position is still the main offensive scoring point, followed by midfielder and defender. The goals of three line players rank in descending order, which is in line with the overall distribution of goals scored in different positions in modern football. At the same time, it reflects the full and defending of modern European football, and the characteristics and development trend of players at different lines being multiskilled, technical and tactical comprehensive, and good at attack and defense.

6. The frontcourt is the main area of attack. The significant rising of the success rate of attacking in the backcourt area is a major feature of the current European Cup, and also indicates that in the modern football game, while ensuring the competition strength of the frontcourt, fast striking back in the backcourt area will also be an way of effective attack besides attack in the frontcourt.
7. The bottom left and bottom right of the goal are the best attack areas with most scores. The middle area facing the goalkeeper scores the least. The upper left and upper right of the goal are the primary choice area of the majority of athletes when having penalty direct free kick.

8. In the modern European soccer match, place near the penalty area is the most threatening shooting area. All teams will pay attention to the area, and strengthen the shooting in the area in the implementation of tactical system. In addition, when the game is in the stalemate stage and is difficult to break in the A, B area, grasping the long-range opportunities at the leading edge of restricted area will help to play a decisive role in winning the game.

\section{REFERENCES}

[1] Cao Weihua. Analyze the Development Rule of Modern Football from the 19th World Cup Soccer Game[J]. China Sports Science and Technology, 2011,47 (1): 65-68.(In Chinese)

[2] Xue Jun, Li Yang, Guo Changjiu. The Team Offensive Goal Characteristics at the Final Stage of The 18th World Cup [J]. China Sports Science and Technology, 2007,43 (1): 36-40.(In Chinese)

[3] Wang Jianming, Zhang Xiangyang. The Team's Offensive Goal Characteristics at the Final Stage of 2008 European Cup Soccer Game [J]. China Sports Science and Technology, 2009,45(1):67-70.(In Chinese)

[4] Guo Tao, Zhang Mingbo. The Study of the Characteristics of 76 Goals at the Final Stage of 2012 European Cup Soccer Game [J]. Sports Culture Guide, 2013, (1): 69-73.(In Chinese)

[5] Yang Ciyu, Li Xianqing, Li Qiuliang. Soccer Game Scoring Law [J]. Journal of Chengdu Physical Education Institute, 2006, 32(3):68-73.(In Chinese)

[6] He Zhilin. Modern football [M]. Beijing: People's Sports Publishing House, 2000: 136-146.(In Chinese)

[7] Xue Jun, Li Yang, Guo Changjiu. The Team Offensive Goal Characteristics at the Final Stage of The 18th World Cup [J]. China Sports Science and Technology, 2007,43 (1): 36-40.(In Chinese)

[8] Xue Jun, et al. Study on the Basic Characteristics and Laws of Modern Soccer Game Goals [J]. Journal of Beijing Sport University, 2015,38(8):125-129.(In Chinese)

[9] Geng Jianhua, Shui Yizhou, The Characteristics of the Goal at the Final Stage of 2012 European Cup Soccer Game [J]. Journal of Nanjing Institute of Physical Education, 2012,26 (4): 110-116.(In Chinese) 